\title{
O estado da arte em psicanálise e educação no Rio Grande do Sul (2000-2016)
}

\author{
Rose Gurski \\ ORCID: 0000-0002-7392-1463 \\ Stéphanie Strzykalski ${ }^{1}$ \\ ORCID: 0000-0001-8958-0387 \\ Paula Gus Gomes ${ }^{1}$ \\ ORCID: 0000-0003-0346-9966 \\ Eugênio Helyantus Stumm ${ }^{1}$ \\ ORCID: 0000-0001-9087-4198
}

\section{Resumo}

Este estudo é parte de uma pesquisa de âmbito nacional realizada pelo Grupo de Trabalho (GT) "Psicanálise e Educação" da Associação Nacional de Pesquisa e Pós-graduação em Psicologia (ANPEPP). Em 2015 o GT produziu e divulgou um grande levantamento de dados de diferentes regiões do Brasil com o intuito de construir um retrato nacional do campo da psicanálise e educação. Tal esforço, que é fruto de outros movimentos semelhantes na área, propiciou uma fotografia das investigações, assim como das metodologias utilizadas pelos diferentes Núcleos e Laboratórios de pesquisas envolvidos com a temática nas diversas regiões do país. Buscando dar continuidade aos estudos mais expressivos acerca do tema supracitado, nossos objetivos são: traçar um panorama da produção acadêmica de psicanálise e educação no Rio Grande do Sul tomando como recorte o período de janeiro de 2000 a agosto de 2016; identificar e problematizar os principais eixos teóricos pesquisados no campo; organizar e potencializar articulações entre os diferentes pesquisadores da área. Para isso, utilizamo-nos do survey bibliográfico como estratégia metodológica no processo de elaboração do levantamento da produção acadêmica. Entendemos que seja relevante aprofundar a perfilação do campo da psicanálise e educação no Rio Grande do Sul, pois essa região esteve implicada em diferentes ondas de produção ao longo do tempo. Com os esforços realizados, almejamos propiciar uma maior sinergia de trabalho entre os pesquisadores do campo, compreender os rumos futuros da área, facilitar trocas entre as temáticas, pensar a ampliação do campo com mais densidade, retratar os caminhos metodológicos e alcançar uma melhoria da qualidade das pesquisas.

1- Universidade Federal do Rio Grande do Sul, Porto Alegre/RS - Brasil.

Contatos: rosegurski@ufrgs.br; stephanie.strzykalski@hotmail.com; paulagusgomes15@gmail.com; eugeniost@ufcspa.edu.br. 


\section{Palavras-chave}

Psicanálise - Educação - Survey bibliográfico.

\section{The state of the art in psychoanalysis and education in Rio Grande do Sul (2000-2016)}

\section{Abstract}

This study is part of a Brazilian research project made by the Working Group (WG) "Psychoanalysis and Education" of the Psychology Research and Graduate National Association (ANPEPP). In 2015, this WG produced and disseminated a big data survey of different Brazilian regions aiming to create a national portrait of the Psychoanalysis and Education field. This effort, which is a result of other similar movements in the area, provided us with a snapshot of the research investigations, as well as the methodologies used by the different Research Centers and Laboratories involved with the theme in the different regions of the country. Seeking to continue conducting the most expressive studies on this theme, our objectives are: trace an overview of the Psychoanalysis and Education academic production circumscribed in the period from January 2020 to August 2016; identify and question the main theoretical axis researched in the field; organize and potentialize articulations among the different researchers of the area. For this purpose, we use the bibliographic survey as a methodological strategy in order to present an overview of academic production. We understand that it is important to deepen the overview of the Psychoanalysis and Education field in the State of Rio Grande do Sul, since this region has been implicated in different production waves throughout the recent years. With these efforts done, our goal is to create a bigger working synergy among the field researchers, to understand future possibilities in the area, to facilitate exchanges between the subjects, to think over the enlargement of the field with more density, to trace possible methodological paths and achieve some improvement in the quality of the researches.

\section{Keywords}

Psychoanalysis - Education - Bibliographic survey. 
Este estudo é parte de uma pesquisa de âmbito nacional desenvolvida pelos membros do GT Psicanálise e Educação da ANPPEP². Esse Grupo, no ano de 2015, produziu e divulgou um grande levantamento de dados de diferentes regiões do Brasil com o intuito de construir um retrato nacional do campo da Psicanálise e Educação. Tal esforço, que é fruto de outros movimentos semelhantes na área, como o de Kupfer et al. (2010), propiciou uma fotografia das investigações, assim como das metodologias utilizadas pelos diferentes Núcleos e Laboratórios de pesquisas envolvidos com a temática nas diversas regiões do país.

Ao circunscrever o perfil das pesquisas, surgiram várias questões a serem debatidas por cada região. Dentre algumas, destacamos as diferentes vocações temáticas que se evidenciaram tanto no volume, como na escolha de algumas áreas específicas de investigação, assim como o perfil do corpo de pesquisadoras responsáveis pela construção de saberes na área. Nesse sentido, somam-se ainda as lacunas na produção científica sobre a sistematização dos trajetos percorridos pela Psicanálise e Educação no Rio Grande do Sul.

Buscamos, portanto, aprofundar a perfilação do campo no Rio Grande do Sul, especialmente por entendermos que nossa região esteve implicada em diferentes ondas de produção ao longo do tempo. Nossa compreensão é de que aspectos políticos, culturais, econômicos, sociais e até mesmo geográficos participaram do estabelecimento e variação de perfis diversos de estudos. Cabe dizer, ainda, que este trabalho busca dar certa continuidade aos estudos mais expressivos acerca do delineamento das investigações da área, como os esforços de Kupfer et al. (2010) e Pereira e Silveira (2015).

De todo modo, sublinhamos ainda que este escrito visa, sobretudo, compreender de que forma vem se estruturando a rede de produção e de transmissão da Psicanálise e Educação no estado, com base no período de 2000 a 2016, bem como identificar e reunir os pesquisadores do campo a fim de adensar a sinergia e a produção nessa área do conhecimento em nossa região.

Em 2015, já como fruto da pesquisa nacional da qual este estudo faz parte, construímos o Seminário Especial "Eixos, rotas e linhas de força no campo da pesquisa em Psicanálise e Educação”. 0 evento, promovido pelo Núcleo de Pesquisa em Psicanálise, Educação e Cultura da Universidade Federal do Rio Grande do Sul (NUPPEC/UFRGS), contou com o apoio do Programa de Pós Graduação em Psicanálise: clínica e cultura (UFRGS), bem como com a parceria do Programa de Pós Graduação em Educação (UFRGS) e da Associação Psicanalítica de Porto Alegre (APPOA). Por meio dessa atividade, foi possível tecermos conexões iniciais com alguns dos protagonistas que conduzem as pesquisas em Psicanálise e Educação na Região Sul. Na época, disparamos um informativo sobre o Seminário aos pesquisadores que já havíamos identificado nas buscas da investigação, tendo, na presença de alguns deles ao longo do evento, a confırmação sobre a importância de ações que reúnam e promovam a interlocução entre os pesquisadores.

Em meio ao evento, apresentamos os caminhos investigativos habitualmente usados na área e problematizamos as metodologias utilizadas nos trabalhos que envolvem a Psicanálise e a Educação. A discussão trazida pelos palestrantes ${ }^{3}$ funcionou como

2- Associação Nacional de Pesquisa e Pós-graduação em Psicologia - biênio 2014-2016.

3- Contamos com a presença do Prof. Dr. Marcelo Ricardo Pereira, do Programa de Pós-graduação em Educação (UFMG), e do Prof. Dr. Rinaldo Voltolini, do Programa de Pós-graduação em Educação (USP). 
disparador para levantar antigos debates no meio acadêmico em diálogo com a comunidade externa. Discutimos, naquele momento, formas possiveis de inserção dos trabalhos locais no cenário nacional e internacional.

Considerando a forte produção no campo da Psicanálise e Educação nos anos de 1990, na cidade de Porto Alegre e no Rio Grande do Sul, o Seminário, bem como a construção do presente artigo, busca, através da nomeação e reconhecimento do que na atualidade vem se produzindo em articulação com o cenário nacional e internacional, retomar alguns caminhos dos trabalhos acadêmicos no campo supracitado na Região Sul do Brasil.

\section{A psicanálise e a educação: o contexto das primeiras conexões}

Mesmo avisados das diferenças epistêmicas que separam o campo da Educação e da Psicanálise, não cessamos de propor sua articulação. Será mero capricho oriundo das nossas mais caras ilusões quanto ao que é possível à educação quando do seu alargamento? Ou será que o sujeito do inconsciente e suas produções são, atualmente, uma aquisição indissolúvel de nosso tempo, uma espécie de patrimônio cultural da humanidade pósfreudiana, em relação a qual não podemos mais passar indiferentes (GURSKI, 2008)?

Desde Freud, foram inúmeras as tentativas de conexões entre ambos. Se a versão profilática da interação já foi, há muito tempo, superada, ainda restam interpretações funcionalistas que, em época de tecnicismos crescentes, tornam, cada vez mais, necessária a discussão sobre as condições e as possibilidades de encontros neste litoral.

Freud, ao inaugurar este diálogo, apostava que nele poderia residir a possibilidade de uma extensão da psicanálise à cultura e a outros campos de conhecimento. Podemos pensar que a esperança de Freud na direção da educação talvez tenha se dado, justamente, como um efeito de seu interesse pela cultura, pois tanto a educação quanto a psicanálise pressupõem a constituição do sujeito, na medida em que pertencem ao que se denomina campo do discurso do outro (GURSKI; PIRES, 2017).

Já na década de 1910, o vienense não escondia a vontade de expansão da Psicanálise para além do meio médico e, para tanto, apostava que a Educação poderia ser um campo de grande retorno ao movimento psicanalítico. Tal aposta não deixava de ter uma relação com as transferências de Freud, no sentido de que alguns de seus discípulos e colegas, com quem mantinha relações de admiração e respeito intelectual, fizeram tentativas de colocar a psicanálise em interlocução com outras áreas do saber.

De modo bastante evidenciado pelas produções e publicações, há uma forte onda, principalmente entre os anos de 1909 e 1913 e, depois, de 1925 a 1926, que desvela a esperança de Freud em ver a Psicanálise na cultura através da Educação. Neste cenário, August Aichhorn, educador e psicanalista austríaco, foi um dos entusiastas da educação psicanalítica, acompanhando Anna Freud em várias de suas construções neste âmbito (GURSKI; MORAES; GOMES, 2016).

É interessante, pois o ano de 1925 é marcado por dois acontecimentos que importam para a história da Psicanálise e da Educação de modo geral. Um deles é a criação do Seminário de Crianças da Sociedade Psicanalítica de Viena. Essa atividade teve também 
uma função política no seio do Movimento Psicanalítico, uma vez que foi fundada após toda a polêmica que envolveu o assassinato brutal de uma das psicanalistas pioneiras no campo da clínica com crianças, Hermine Hug-Helmuth (ROUDINESCO; PLON, 1998). Toda essa situação dramática produziu o acirramento das resistências na Viena conservadora e já bastante refratária à Psicanálise da época (ROUDINESCO, 2016 apud GURSKI; PIRES, 2017).

Juntou-se também a esse cenário a discussão sobre a análise leiga através da acusação de charlatanismo feita a Theodor Reik. Em fevereiro de 1925, Reik foi proibido judicialmente de exercer a Psicanálise por não ser médico. Freud (2010 [1926], p. 219220), no texto que escreve acerca do processo de Reik e do tema da análise leiga, diz que "o que importa não é se o analista possui ou não um diploma de medicina, mas se adquiriu a formação especial que o exercício da análise requer”.

Em meio a essas circunstâncias, a potência da educação como campo de difusão da Psicanálise passou a ganhar um vulto maior. Nesse cenário de disputas conceituais e corporativas, acabou por se amalgamarem questões da análise leiga, da psicanálise com crianças e das interlocuções da Psicanálise com a Educação.

Dentre as tantas posições dessas interlocuções, tivemos um momento mais inicial e iluminista de Freud, quando ele pensou na possibilidade da Psicanálise fazer prevenção de neuroses a partir de esclarecimentos didáticos quanto à sexualidade infantil (FREUD, 1996 [1908]). Nessa mesma esteira de pensamento, temos a indicação de análise aos educadores como efeito do encontro com a educação. Mais ao final de seus escritos sobre as conexões possíveis entre Psicanálise e Educação, ele deixa como questão às futuras gerações, a possibilidade de pensar em articulações ainda não imaginadas.

Da aplicação à implicação, das ações mais higienistas e colonizadoras à rica noção de que é preciso lidar com a alteridade dos campos, chegamos aos anos 2000 ainda inundados pelo fascínio das inúmeras possibilidades que podem se construir em meio a esse encontro. Vejamos, de maneira geral, o movimento destas articulações que se apresentaram no Brasil e, mais especificamente, no Rio Grande do Sul.

\section{Psicanálise e educação: um tema para os trópicos}

A interseção entre os campos da Psicanálise e Educação começou a se fazer presente no Brasil já na década de 1930, com alguns autores que se propunham a aplicar a psicanálise à educação (KUPFER et al., 2010). Cabe destacar Arthur Ramos, na década de 1930, e suas teses psicanalíticas enquanto ferramentas educacionais que poderiam ser aplicadas de forma benéfica às escolas (SIRCILLI, 2005). De caráter higienista, não é difícil concluir que as produções desse período utilizavam a Psicanálise como um instrumento em prol do ajustamento do aluno à escola (ABRÃo, 2006).

Sabemos que a onda profilática que cultivava a aplicação da Psicanálise à Educação não decolou muito além da década de 1920. Freud (1969 [1925]) afirmava que não se poderia tomar somente tal dimensão da Psicanálise - o trabalho educativo é sui generis e não deve ser confundido com a intervenção terapêutica. Em 1933, já mais perto da noção das impossibilidades, Freud (2006 [1933]), abordará os limites da educação. 
Ao longo da década de 1930, vemos Freud dizer suas últimas palavras sobre as ditas conexões. Em 1937, ele expôs os limites de uma aproximação entre a psicanálise e a educação em Análise terminável e interminável. Importa destacar que, nesse mesmo ano, ocorreu também o fechamento da Revista de Pedagogia Psicanalítica, lançada em 1926, tal revista recebeu muitas produções no âmbito da aplicação da psicanálise. Foi um tempo de intensas construções, porém os ventos sombrios da década de 1930 e a aproximação com as restrições ao livre pensar a partir do crescimento dos totalitarismos na Europa contribuíram enquanto variáveis que fizeram com que essa discussão ficasse apagada.

Torna-se interessante pensar nos impactos desta movimentação, sobretudo no Brasil, pois é justamente na década de 1930 que tal discussão chega aos trópicos, pelas mãos do já referido Arthur Ramos. Inicialmente, a dimensão higienista desta conexão remetenos aos primórdios das ideias freudianas, quando a função da Psicanálise era prevenir as neuroses através do esclarecimento.

A discussão chega ao Brasil no momento em que entra em declínio, na Europa, o debate maior sobre as interlocuções do campo. Assim, apesar de algumas iniciativas isoladas, sabemos que os enlaces entre Psicanálise e Educação passaram por um retraimento significativo ao longo das quatro décadas seguintes também no Brasil (KUPFER et al., 2010). Após os anos de 1930, é como se as discussões sobre o tema tivessem entrado em latência. Todavia, gradativamente, alguns trabalhos sobre Psicanálise com crianças e adolescentes foram, aos poucos, retomando o vigor da conexão Psicanálise-Educação.

Fora do Brasil tivemos algumas produções que se aproximaram fortemente deste diálogo. Dentre essas, sublinhamos o trabalho vigoroso de Melanie Klein com a psicanálise de crianças e Françoise Dolto com bebês. Dentre as intervenções criativas que surgiram, sublinhamos também a criação, em 1969, da École de Bonneuil concebida por Maud Mannoni - psicanalista responsável por lançar um novo modo da Psicanálise se relacionar com a Educação no âmbito das psicopatologias da infância e adolescência.

Estes foram trabalhos que surgiram justamente nas décadas de silenciamento entre 1930 e 1980. Segundo Kupfer et al. (2010), o hiato de silêncio que se interpôs neste período foi rompido após os anos 1980, quando ocorreu uma nova onda de produções no campo. Importa destacar que, no Brasil, após todo o referido período de silenciamento, voltamos a falar de Psicanálise e Educação a partir do grupo de São Paulo, mais especificamente da Universidade de São Paulo (USP). Este grupo ${ }^{4}$ articula a proposição de trabalhar da aplicação à implicação, de modo a gerar uma outra forma de encontro diferente da justaposição e da intersecção, cunhando uma nova expressão: a educação atravessada pela psicanálise. Deste modo, algo do "fazer no entre" dois campos passou a ter um nome próprio, chamando-se "educação para o sujeito” (KUPFER et al., 2010, p. 290).

4- Psicanalistas como Maria Cristina Kupfer e Leandro Lajonquière, ambos docentes da USP, assim como Rinaldo Voltolini, com suas produções no campo, deram vigor a uma certa direção deste diálogo. Lembramos também o importante papel do GT de Psicanálise e Educação da ANPEPP que nasceu no ano de 2006 e que passou a liderar politicamente o campo com docentes-pesquisadores de diferentes IES - Instituições de Ensino Superior - do país, representando a diversidade regional, sob a denominação Psicanálise, Infância e Educação. 


\section{Psicanálise e educação no Rio Grande do Sul e em Porto Alegre}

É interessante perceber como cada região constrói diferentes caminhos de produção atravessados por uma infinidade de variáveis. Como já referido anteriormente, os efeitos do boom de produção, após a década de 1980 foram sentidos especialmente nos anos de 1990, momento em que uma conjuntura política e social fez de Porto Alegre uma das primeiras capitais a ter um partido de trabalhadores na gestão municipal. Tal condição, na época, trouxe, ao campo da educação, uma série de projetos de franco desenvolvimento social, educacional e cultural.

Entre 1989 e 1992, tivemos como Secretária de Educação do Município de Porto Alegre a educadora Esther Pillar Grossi, uma das fundadoras do Grupo de Estudos sobre Educação, Metodologia da Pesquisa e Ação (GEEMPA). De inspiração pós-construtivista, o GEEMPA é uma ONG com 47 anos de atuação, sendo que sua fundação se deu em 1970, primeiramente, como Grupo de Estudos sobre o Ensino da Matemática de Porto Alegre com a finalidade de proporcionar aos alunos o gosto por esta matéria. Passados alguns anos, o Grupo passou a se focar na alfabetização, com o intuito de enfrentar o grande desafio de reduzir as taxas de analfabetismo no Brasil.

No período de atuação de Esther Grossi na Secretaria de Educação do município, Porto Alegre tornou-se uma referência no campo da inclusão educacional. Tivemos vários projetos de vanguarda na educação, na época, dita especial. Foi um momento de efervescência política e social com efeitos plurais para as intervenções educacionais. Foi também neste momento histórico que, através de um convênio entre a Prefeitura de Porto Alegre e a Faculdade de Educação da UFRGS, tivemos a construção do Projeto Criança Psicótica e a Escola Pública. Tal projeto trazia a experiência da já citada École de Bonneuil para nossas construções acerca do tema da inclusão. Neste tempo potente de criações, a Psicanálise, em conexão com a Educação em nossa cidade, protagonizou um capítulo importante de vanguardismo nas reflexões educacionais da região, especialmente referentes à inclusão de sujeitos autistas, psicóticos e deficientes mentais. A ideia era que esses sujeitos pudessem circular no âmbito da escolarização.

Outra influência formativa que tivemos em Porto Alegre foi a repercussão da chegada ao Rio Grande do Sul dos psicanalistas argentinos que vieram após o golpe militar em seu país. Especificamente, no campo da Psicanálise e Educação, em 1979, foi fundado, em Porto Alegre, o Centro Lydia Coriat. Com essa instituição, foi inaugurado um importante espaço de atendimento à infância, sobretudo à infância com transtornos do desenvolvimento (GAGEIRO; TOROSSIAN, 2014). A transmissão e a formação de várias gerações de psicólogos, psicanalistas e educadores pelo Centro trouxe um tom não só psicanalítico, mas um modo transdisciplinar de tomar as questões do desenvolvimento na infância e adolescência, isso tanto do ponto de vista clínico como educacional. 0 Centro tornou-se, ao longo dos anos, um importante lugar de pesquisa e de formação no campo da psicanálise com crianças e adolescentes.

Tomamos esses dois recortes históricos como variáveis que participaram da onda de construção de espaços oficiais e de vanguardismo no campo da inclusão educacional nos 
anos 1990 no Rio Grande do Sul. Em particular, em Porto Alegre houve uma onda intensa de inovação e criação no campo da Psicanálise e Educação. Todo este capital intelectual acabou produzindo também a abertura de inúmeras clínicas privadas ${ }^{5}$ com equipes multi e interdisciplinares que passaram a ofertar atendimento clínico e educacional para sujeitos com transtornos de desenvolvimento.

Na referida década de 1990 e início dos anos 2000, as políticas públicas de inclusão foram potencializadas, fazendo surgir um ambiente favorável à tolerância em relação às diferenças cognitivas, sociais e psíquicas de crianças e adolescentes. Após esse período, e tendo na sequência um esvaziamento do ideário social e político da cidade e do Estado, ocorreu que as alternâncias de governo, cujas lideranças não souberam sublinhar a importância da manutenção de Programas de Estado, tiveram como efeito uma derrocada das políticas inclusivas no município. Isso, a nosso ver, produziu uma terceira onda cuja característica mais marcante talvez tenha sido a de plasmar um certo efeito platô, isto é, de estagnação, no campo.

\section{Estratégias metodológicas: survey bibliográfico}

Partimos do objetivo de traçar um panorama da produção acadêmica de Psicanálise e Educação no Rio Grande do Sul de janeiro de 2000 a agosto de 2016, identificar e problematizar os principais eixos teóricos pesquisados no campo, assim como organizar e potencializar articulações entre os diferentes pesquisadores da área. Nesse sentido, reunimos nossos esforços norteados pela pergunta de pesquisa "Qual a produção acadêmica no Rio Grande do Sul sobre o campo da Psicanálise e Educação entre 2000 e 2016 e qual o perfil de quem a produz?".

Ao tomar como norte a tradição de trabalhos realizados por Kupfer et al. (2010) e Pereira e Silveira (2015), utilizamo-nos do survey bibliográfico como estratégia metodológica no processo de elaboração do levantamento da produção acadêmica - dissertações, teses, artigos e livros - de Psicanálise e Educação no Rio Grande do Sul. Nesse sentido, as principais fontes de busca foram: o banco de Teses e Dissertações da Capes, o Google Acadêmico, o SciElo e o BVS-Psi. Em combinação com o termo "psicanálise", fizemos diversas buscas com as seguintes palavras-chave: Educação; Escola; Inclusão; Psicose; Autismo; Escrita; TGD; Transtorno Global Do Desenvolvimento; Socioeducação; Ato Infracional; Professor; Formação; Ensino-Aprendizagem; Aprendizagem; Alfabetização; Fracasso Escolar; Mal-Estar + Educação.

Consideramos apenas as produções acadêmicas inseridas no campo da Psicanálise e Educação do Estado do Rio Grande do Sul de autoras e autores que: (a) estiveram/estão vinculados/as a uma Instituição de Ensino Superior do Rio Grande do Sul, no período que compreende do ano de 2000 a agosto de 2016, com titulação de mestre, doutorando/a, doutor/a ou professor/a pesquisador/a; (b) produziram suas contribuições ao campo de Psicanálise e Educação durante o período supracitado; (c) produziram materiais que se encontram disponibilizados online e com acesso gratuito.

5- Dentre outras, destacamos os trabalhos realizados na Clínica Interdisciplinar Maud Mannoni, no Mosaico Centro Interdisciplinar e na Clínica Palavra Viva. 
A listagem final resultou em 173 trabalhos entre teses, dissertações, artigos e livros. Identificamos 68 pesquisadores envolvidos, desses, 41 estavam, no período da pesquisa, ligados à universidade como docentes ou pós-graduandos. A partir do acervo que resultou de nossas investigações, passamos a fazer uma análise de palavras-chaves, dos resumos e/ou de textos integrais, dos quais extraímos seus respectivos objetos de estudo. Esse procedimento de pesquisa mais refinado teve o intuito de poder classificá-los, quantificálos e agrupá-los em eixos temáticos que foram sendo construídos a partir da emergência das temáticas dos materiais analisados: 1. Psicanálise, Educação e Inclusão; 2. Psicanálise, Socioeducação e Violência juvenil; 3. Transmissão; 4. Psicanálise, Produções da cultura contemporânea e Processos de subjetivação; 5. Mal-estar na Educação e Formação de Professores; 6. Educação Infantil e Psicanálise; 7. Outras Categorias.

Com base nas categorias temáticas que surgiram, reagrupamos as produções em arquivos separados para que pudessem receber vários tratamentos, a fim de que fosse possível serem discutidos. Com essa medida, nosso objetivo foi poder extrair o resumo dos conteúdos que os trabalhos originalmente apresentavam para traçar o panorama deste escrito. Daí retiramos a matéria-prima para construir, da forma mais representativa, abrangente e emblemática possível, a súmula para cada categoria temática aqui proposta.

\section{Sobre os eixos temáticos}

1) Transmissão: foram encontrados 43 trabalhos (aproximadamente $24,85 \%$ do total) sobre o tema. Esses foram produzidos por 17 pesquisadores, sendo que 11 deles estavam ligados à universidade. Haja vista a quantidade significativa de trabalhos circunscrita na categoria Transmissão, em consonância com a amplitude do tema, dividiu-se essa em três subcategorias.

$\mathrm{Na}$ primeira, Escrita, literatura e transmissão, observou-se o destaque dado para discutir e problematizar temas como a transmissibilidade do saber e da experiência, escrita, alteridade, formação de professores e o processo de escuta. 0 tema de maior repercussão foi da leitura e escrita com psicóticos, o que também pode ser entendido como interseccionado ao âmbito da educação especial. Na categoria seguinte, Transmissão da psicanálise, retoma-se o debate acerca da transmissão e ensino da psicanálise na universidade, incluindo o contexto da clínica-escola na universidade pública, assim como aspectos de ensino empregados por Jacques Lacan. Na terceira categoria, que denominamos de Processos de ensino-aprendizagem e suas dificuldades, houve notória ênfase dada a temas como alteridade, linguagem, sintoma, saber e escola.

2) Psicanálise, educação e inclusão: foram encontrados 39 trabalhos (22,54\% do total) sobre a temática. Esses foram produzidos por 16 pesquisadores, sendo que 5 deles estavam ligados à universidade. Os assuntos abordados nesse eixo temático são bastante amplos, todavia, destacamos alguns deles. A maior parte dos trabalhos propõe um apanhado histórico da educação especial no Brasil, o que leva a problematizações acerca da implementação de novas diretrizes nesse campo. Além disso, muitos trabalhos versam sobre a relação entre desses alunos e seus professores, enfocando nas formas que os docentes encontram para lidar com essas crianças que fogem do "padrão". Ainda, várias produções 
têm como alvo de seus questionamentos as crianças que estão pela via do autismo e da psicose, problematizando o modo como os diagnósticos estavam sendo feitos.

3) Psicanálise, produções da cultura contemporânea e processos de subjetivação: foram encontrados 32 trabalhos $(18,50 \%$ do total) sobre a temática. Esses foram produzidos por 5 pesquisadores, sendo que quatro deles estavam ligados à universidade. As produções da categoria "Psicanálise, produções da cultura contemporânea e processos de subjetivação" podem ser divididas em duas fortes correntes, ainda que estas se apresentem muitas vezes interseccionadas. Por um lado, houve uma significativa produção sobre temas como subjetividade, experiência, juventude, infância e adolescência, por outro, destaca-se uma grande ênfase na problematização e análise de produções audiovisuais, como cinema, fotografia, televisão e imagem (em movimento). Em consonância, ainda observamos trabalhos dedicados a pensar a cidade, a arte, o brincar e a criança a partir de uma concepção de Educação atravessada pela Psicanálise.

4) Educação infantil e psicanálise: foram encontrados 27 trabalhos (15,60\% do total) sobre o tema. Esses foram produzidos por 13 pesquisadores, sendo que 11 deles estavam ligados à universidade. Os trabalhos abarcados na categoria "Educação infantil e Psicanálise" exploraram o tema de maneiras bastante fragmentadas entre si. É possível conjecturar que esse fenômeno ocorra devido ao grande número de pesquisadores em relação aos trabalhos (1,7 para cada pesquisador). Ainda assim, foram recorrentes os trabalhos que tratam de temas como criatividade, subjetividade, autoridade, professores, problemas de aprendizagem, o brincar e o período de latência. Em menor número, também foram encontrados trabalhos propondo pensar a psicose na infância, bebês e suas relações com as mães, tecnologias, ética e interdisciplinaridade.

5) Mal-estar na educação e formação de professores: foram encontrados 12 trabalhos $(6,93 \%$ do total) sobre o tema. Esses foram produzidos por 10 pesquisadores, sendo que 3 deles estavam ligados à universidade. Os temas variam bastante dentro deste eixo temático, mas podemos afirmar que as temáticas mais discutidas são as problemáticas referentes à relação professor-aluno e o mal-estar na educação, tendo como pano de fundo o mundo contemporâneo. Várias pesquisas se propõem a serem meramente teóricas. No que se refere às pesquisas que se utilizaram da experiência para problematizar e refletir sobre as temáticas, poucos se propõem a realizar algum tipo de intervenção no campo, produzindo uma análise da mesma.

6) Outras categorias: foram encontrados 12 trabalhos (6,93\% do total). Esses foram produzidos por 6 pesquisadores, sendo que 5 deles estavam ligados à universidade. Por se tratar de uma categoria bastante ampla, aqui acentua-se a heterogeneidade nos trabalhos encontrados. No entanto, é considerável o número de produções envolvendo gênero e sexualidade no âmbito da Psicanálise e Educação, incluindo seus desdobramentos para parentalidade e maternidade. 
7) Psicanálise, socioeducação e violência juvenil: foram encontrados 8 trabalhos $(4,62 \%$ do total) sobre a temática. Esses foram produzidos por 5 pesquisadores, sendo que 2 deles estavam ligados à universidade. 0 fio condutor mais marcante entre os trabalhos é a intenção de refletir acerca dos motivos e significados possíveis dos atos infracionais. Dentre as pesquisas, destaca-se o uso de entrevistas semiestruturadas e da análise de conteúdo. Também é marcante o questionamento acerca da forma com que as funções parentais foram exercidas na vida dos adolescentes que cometem atos infracionais. Apesar de todos os trabalhos serem atravessados pelo tema da adolescência, poucos se dedicam a pensar sobre ela. Os temas mais discutidos nas pesquisas deste eixo temático são a parentalidade, a lei e o desamparo.

\section{Algumas considerações finais}

Conforme Abrão (2006), nas primeiras décadas de 1900, as conexões da Psicanálise com a Educação tinham como principal proposta as práticas higienistas e profiláticas, sendo que a intervenção preventiva por intermédio da educação constituía um eixo central, justificando a divulgação da Psicanálise no meio educacional. Em nosso trabalho, todavia, foi possível perceber que a área problematiza as subjetividades e as manifestações contemporâneas, além de ir em direção a uma prática que busca a formação integral daqueles em posição de educador-sujeito e aluno-sujeito, permitindo o encontro com a experiência e as vivências inconscientes.

Sobre as dificuldades da pesquisa, sublinhamos o número considerável de produções indisponíveis online, bem como de materiais não indexados nos bancos de dados utilizados no survey. Nesse sentido, faz-se presente a compreensão de que nosso trabalho é um esforço ciente da impossibilidade de abarcar todos os registros da área.

Com os esforços realizados, almejamos propiciar ao campo uma maior sinergia de trabalho entre os pesquisadores, compreender os rumos futuros da área, facilitar trocas entre as temáticas, pensar a ampliação do campo com mais densidade, retratar os caminhos metodológicos, assim como alcançar uma melhoria da qualidade das pesquisas.

A partir da leitura dos textos de Kupfer et al. (2010) e Pereira e Silveira (2015), foi possivel observar algumas semelhanças e, também, algumas diferenças. A pesquisa de Kupfer et al. (2010) se propunha a fazer um survey bibliográfico das produções brasileiras a partir de 1980, enquanto Pereira e Silveira (2015) propõem a mesma pesquisa, mas utilizando materiais do universo de 1987 até 2012; uma leitura de ambos artigos nos apresenta uma certa narrativa da construção de um campo de intersecções entre Psicanálise e Educação no contexto brasileiro.

Observamos, em uma perspectiva de leitura de caráter quantitativo e comparativo, que as pesquisas ligadas à subjetividade, à contemporaneidade e ao trabalho com professores se destacam tanto em nossa pesquisa quanto nos achados de Kupfer et al. (2010) e de Pereira e Silveira (2015). A inclusão também é temática relevante em todos os surveys. Pereira e Silveira (2015) nos apresentam uma quantidade significativa de produções voltadas à adolescência, o que não aparece de maneira tão pungente em nossa amostra e na de Kupfer et al. (2010). Podemos construir hipóteses de que as pesquisas 
no campo da psicanálise, educação e adolescência cresceram nas últimas décadas, mas demoraram para chegar na região sul através de estudos acadêmicos - por isso ainda não se destacaram em nossa amostra.

Registramos que, no âmbito acadêmico, tais trabalhos vinham sendo produzidos especialmente no PPG da Faculdade de Educação da UFRGS e que, a partir de 2015, com a chegada do PPG "Psicanálise: clínica e cultura", do Instituto de Psicologia (UFRGS), o Estado passou a contar com um novo polo de produção acadêmica acerca da articulação entre Psicanálise e Educação. Junto a esse novo momento nasceu, em 2012, o NUPPEC - Núcleo de Pesquisa em Psicanálise, Educação e Cultura (UFRGS), grupo composto por docentes da Faculdade de Educação e do Instituto de Psicologia da UFRGS. O NUPPEC parte do princípio de que potencializar a discussão em um espaço acadêmico pode lançar efeitos tanto para a formação docente, quanto para a própria Psicanálise que não só "interfere" na Educação, como também de algum modo, acaba "ferida" por este campo de saber ${ }^{6}$. Nesse sentido, trabalham na direção de que as pesquisas realizadas possam sustentar reflexões e espaços de trabalho junto às políticas públicas de educação e cultura, através de cursos de extensão e assessorias a serviços, a instituições sociais e educacionais.

Uma questão subjacente a essa pesquisa é a interrogação acerca da relação que se estabelece entre a psicanálise e a educação nas produções brasileiras - e em nossa análise, na região sul. Pereira e Silveira (2015) e Kupfer et al. (2010) encontram três formas de ler essa relação: a justaposição, em que os campos são analisados de forma separada; a psicanálise como mestre e diretriz interpretativa; e a psicanálise não como exterior à educação e nem como forma de explicar certos fenômenos, mas como uma aliança entre saberes que, juntos, criam um terceiro. Kupfer et al. (2010) ainda propõem as noções de psicanálise aplicada e implicada ${ }^{7}$ para analisar os trabalhos que encontraram em sua pesquisa.

$\mathrm{Na}$ esteira do pensamento da psicanálise implicada, temos trabalhado com a noção de encontro (GURSKI, 2019) para pensar as conexões entre Psicanálise e Educação. Situados mais especificamente no campo da Socioeducação, temos nos dedicado à construção de dispositivos de pesquisa e intervenção em saúde mental infanto-juvenil em contextos que alargam as bordas da clínica e os muros da universidade (GURSKI; STRZYKALSKI, 2018a, 2018b, 2018c). A ideia do encontro nasce de algumas inquietações de cunho metodológico: como a escuta psicanalítica pode operar em sítios tão diferentes do tradicional consultório? Quais efeitos de afetação ocorrem para a Psicanálise, bem como para a Educação, na medida em que se introduz um dispositivo clínico em um cotidiano institucional como, por exemplo, na escola ou na socioeducação (GURSKI; ROSA, 2018; GURSKI, 2019)? Entendemos que, nestes espaços, ganham os sujeitos que podem sorver dos efeitos do trabalho entre fronteiras, naquelas situações em que o laço social parece à beira de se desfazer (PEREIRA, 2016).

6- Fazemos referência às expressões utilizadas pelo Prof. Dr. Rinaldo Voltolini durante a Conferência "Psicanálise e Educação" proferida durante a "I Jornada do NUPPEC - Eixos, rotas e linhas de força no campo da pesquisa em psicanálise e educação", realizada nas dependências da UFRGS em outubro de 2015.

7- Segundo Kupfer et al. (2010), a psicanálise aplicada "sobrevoa e interpreta o educativo, em uma relação de tipo total que tudo sabe: uma relação de mestria" (p. 289). Já a psicanálise implicada coloca o psicanalítico no âmago do educativo ao não descolar a criança de sua dimensão de sujeito, perspectiva essa que amplia, portanto, "0 ato educativo de modo a incluir sua dimensão libidinal, constitutiva e implicada na construção do sujeito do desejo" (p. 290). 
Tais interrogações são necessárias, uma vez que compreendemos que não se trata de ir ao campo educativo para "escutá-lo". Tampouco se trata de insistirmos em uma clínica psicanalítica na, ou em, educação. Trata-se, sobretudo, de pensarmos a partir dos efeitos que podem advir do encontro entre ambas, buscando, no âmbito da pesquisa, que a experiência possa gozar do protagonismo de nossas construções, sem descuidarmos dos fundamentos da Psicanálise, em cenários que, tantas vezes, rechaçam as produções do inconsciente (GURSKI, 2019).

\section{Referências}

ABRÃO, Jorge Luís Ferreira. As influências da psicanálise na educação brasileira no início do século XX. Psicologia, Brasília, DF, v. 22, n. 2, p. 233-239, 2006.

FREUD, Sigmund. Análise terminável e interminável. In: FREUD, Sigmund. Edição standard brasileira das obras psicológicas completas de Sigmund Freud. Tradução de J. Salomão. v. 23. Rio de Janeiro: Imago, 1996 [1937]. p. 225-231.

FREUD, Sigmund. A questão da análise leiga: diálogo com um interlocutor imparcial. In: FREUD, Sigmund. Obras completas. Tradução de P. C. Souza. v. 17. São Paulo: Companhia das Letras, 2010 [1926]. p. 271-341.

FREUD, Sigmund. Moral sexual "civilizada" e doença nervosa moderna. In: FREUD, Sigmund. Edição standard brasileira das obras psicológicas completas de Sigmund Freud. Tradução de J. Salomão. v. 9. Rio de Janeiro: Imago, 1996 [1908]. p. 187-213.

FREUD, Sigmund. Novas conferências introdutórias de psicanálise - Conferência XXXIV explicações, aplicações e orientações. In: FREUD, Sigmund. Edição standard brasileira das obras psicológicas completas de Sigmund Freud. Tradução de J. Salomão. v. 12. Rio de Janeiro: Imago, 2006 [1933]. p. 167-191.

FREUD, Sigmund. 0 mal-estar na civilização. In: FREUD, Sigmund. Edição standard brasileira das obras psicológicas completas de Sigmund Freud. Tradução de J. Salomão. v. 21. Rio de Janeiro: Imago, 1996 [1930]. p. 67-150.

FREUD, Sigmund. Prefácio a 'Juventude desorientada', de Aichhorn. In: FREUD, Sigmund. Edição standard brasileira das obras psicológicas completas de Sigmund Freud. v. 19. Tradução de J. Salomão. Rio de Janeiro: Imago, 1969 [1925]. p. 307-308.

GAGEIR0, Ana Maria; TOROSSIAN, Sandra. A história da psicanálise em Porto Alegre. Analytica Revista de Psicanálise, São João Del-Rei, v. 3, n. 4, p. 117-144, 2014.

GURSKI, Rose. A escuta-flânerie como efeito ético-metodológico do encontro entre psicanálise e socioeducação. Revista Tempo Psicanalítico, Rio de Janeiro, v. 51, n. 2, p. 166-194, 2019. 
GURSKI, Rose. Juventude e paixão pelo real: problematizações sobre experiência e transmissão no laço social atual. 2008. 219 f. (Tese de Doutorado) - Faculdade de Educação, Universidade Federal do Rio Grande do Sul, Porto Alegre, 2008.

GURSKI, Rose; MORAES, Larissa; GOMES, Paula. Aichhorn: uma obra abandonada? SIG: Revista de Psicanálise, Porto Alegre, v. 5, p. 63-72, 2016.

GURSKI, Rose; PIRES, Luísa Puricelli. Uma leitura particular das conexões de Freud com a educação. Aprender - Cadernos de Filosofia e Psicologia da Educação, Vitória da Conquista, v. 17, p. 01-15, 2017.

GURSKI, Rose; ROSA, Miriam Debieux. Psicanálise, socioeducação e a construção da escuta-flânerie. Correio da APPOA, Porto Alegre, n. 282, 2018. Disponível em: http://www.appoa.com.br/correio/edicao/282/ psicanalise_socioeducacao_e_a_construcao_da_escuta_flanerie/648. Acesso em: 02 out. 2019.

GURSKI, Rose; STRZYKALSKI, Stéphanie. A escuta psicanalítica de adolescentes em conflito com a lei que ética pode sustentar esta intervenção? Revista Tempo Psicanalítico, Rio de Janeiro, v. 50, p. 72-98, 2018a.

GURSKI, Rose; STRZYKALSKI, Stéphanie. A 'Invencionática' na pesquisa em psicanálise com adolescentes em contextos de violência e vulnerabilidade: narrando uma trajetória de pesquisa. In: BRASIL, Katia Tarouquella; ALMEIDA, Sandra Francesca Conte; DRIEU, Didier (org.). Proteção à infância e à adolescência: intervenções clínicas, educativas e socioculturais. Brasília, DF: Cátedra Unesco de Juventude, Educação e Sociedade, 2018b. p. 127-139. Disponível em: https://socialeducation.files.wordpress.com/2018/09/ livro-protec3a7c3a3o-c3a0-infc3a2ncia-e-c3a0-adolescc3aancia-web.pdf. Acesso em: 02 out. 2019.

GURSKI, Rose; STRZYKALSKI, Stéphanie. A pesquisa em psicanálise e 0 "catador de restos": enlaces metodológicos. Revista Ágora, Rio de Janeiro, v. 21, p. 406-415, 2018c.

KUPFER, Maria Cristina et al. A produção brasileira no campo das articulações entre psicanálise e educação a partir de 1980. Estilos da Clínica, São Paulo, v. 15, n. 2, p. 284-305, 2010.

PEREIRA, Marcelo Ricardo. 0 nome atual do mal-estar docente. Belo Horizonte: Fino Traço, 2016.

PEREIRA, Marcelo Ricardo; SILVEIRA, Wegis Herculano. Análise do estado da arte em psicanálise e educação no Brasil (1987-2012). Estilos da Clínica, São Paulo, v. 20, n. 3, p. 369-390, 2015.

ROUDINESCO, Elizabeth; PLON, Michel. Dicionário de psicanálise. Rio de Janeiro: Zahar, 1998.

SIRCILLI, Fabíola. Arthur Ramos e Anísio Teixeira na década de 1930. Paidéia, Ribeirão Preto, v. 15, n. 31, p. 185-193, 2005.

Recebido em: 04.06.2019

Revisado em: 01.10.2019

Aprovado em: 08.10.2019 
Rose Gurski é professora do Instituto de Psicologia da UFRGS, orientadora e coordenadora do Programa de Pós-graduação de Psicanálise: clínica e cultura da Universidade Federal do Rio Grande do Sul - UFRGS (2018-2021). Pesquisadora colaboradora do Laboratório de Psicanálise, Sociedade e Política - PSOPOL/USP. Pós-doutoranda do Instituto de Psicologia da USP. Coordenadora do Núcleo de Pesquisa em Psicanálise, Educação e Cultura (NUPPEC Eixo 3/UFRGS). Membro da Rede Internacional Coletivo Amarrações e da Rede Interamericana de Pesquisa em Psicanálise e Política (REDIPPOL). Autora do livro Três Ensaios sobre Juventude e Violência (Escuta, 2012) e uma das organizadoras do livro Retratos da Pesquisa em Psicanálise e Educação (Contracorrente, 2020).

Stéphanie Strzykalski é psicóloga Clínica (UFRGS). Mestre em Psicanálise: clínica e cultura (UFRGS). Pesquisadora vinculada ao eixo Psicanálise, Educação, Adolescência e Socioeducação do Núcleo de Pesquisa em Psicanálise, Educação e Cultura (NUPPEC/UFRGS).

Paula Gus Gomes é graduanda em psicologia na Universidade Federal do Rio Grande do Sul (UFRGS).

Eugênio Helyantus Stumm é graduando em psicologia na Universidade Federal de Ciências da Saúde de Porto Alegre (UFCSPA). 